\title{
CONFRONTO TRA DUE SAGGI DI PCR PER LA
}

DIAGNOSI DI LABORATORIO DI AMEBIASI

\author{
Calderaro A., Gorrini C., Bommezzadri S., Piccolo G., \\ Dettori G., Chezzi C.
}

Dipartimento di Patologia e Medicina di Laboratorio,

Sezione di Microbiologia, Università degli Studi di Parma.

Introduzione. L'identificazione di Entamoeba histolytica, agente eziologico di amebiasi intestinale ed extraintestinale, è di estrema importanza ai fini di una diagnosi corretta e di una terapia mirata. Entamoeba histolytica è morfologicamente identica alla specie non patogena $E$. dispar; pertanto si rendono necessari metodi specifici in grado di distinguerle. Qui riportiamo il confronto tra due saggi di PCR per l'identificazione di E. histolytica e E. dispar in campioni di pazienti con sospetta parassitosi.

Metodi. Il DNA estratto da 163 campioni appartenenti a 108 pazienti, italiani e stranieri (155 campioni di feci, 7 campioni di liquido da ascessi epatici e una biopsia intestinale) è stato sottoposto ad un saggio di Real-Time PCR e ad un saggio di PCR convenzionale per l'identificazione di E. histolytica e E. dispar. Gli stessi campioni sono stati sottoposti a esame parassitologico completo comprensivo di coltura per protozoi intestinali.

Risultati. I due saggi di PCR hanno dato risultati concordanti: sono stati diagnosticati 6 casi di amebiasi da $E$. histolytica e 9 casi di infezione da E. dispar. Il confronto tra i risultati degli esami microscopico e colturale e dei saggi di PCR ha rivelato che questi ultimi sono più sensibili e specifici dei metodi tradizionali i quali, nella nostra esperienza, hanno sottostimato le infezioni da E. histolytica e E. dispar.

Discussione. I saggi di PCR si sono rivelati sensibili, specifici, vantaggiosi in termini di costo-beneficio e applicabili per la diagnosi di amebiasi in pazienti italiani e stranieri provenienti da aree endemiche per amebiasi. Questi saggi permettono una diagnosi rapida, accurata e consentono di instaurare prontamente una terapia mirata dell'amebiasi che se non tempestivamente diagnosticata e trattata può risultare letale. Inoltre, tali saggi si sono dimostrati utili per ottenere informazioni, attualmente scarse, riguardanti l'epidemiologia delle infezioni da E. histolytica e E. dispar in paesi non endemici come l'Italia, in accordo con le raccomandazioni dell'Organizzazione Mondiale della Sanità. 